Check for updates

Montreal

Cite this as: BMJ 2021;373:n1000 http://dx.doi.org/10.1136/bmi.n1000 Published: 16 April 2021

\title{
Covid-19: US reports low rate of new infections in people already vaccinated
}

\section{Owen Dyer}

The US Centers for Disease Control and Prevention knows of about 5800 "breakthrough" infections of SARS-CoV-2 so far among the roughly 77 million people in the country who have been fully vaccinated, the agency has said.

The low figure gives reassurance than the promising results seen in clinical studies of the Pfizer and Moderna vaccines, which account for the overwhelming majority of jabs given so far in the US, are being reproduced in real world conditions.

The CDC released the figure in a 15 April email to news organisations. The 5800 cases included 74 patients who died from covid-19 and 396 who were admitted to hospital.

Just under a third (29\%) of the identified cases were asymptomatic, about twice the rate seen in unvaccinated patients. Two thirds $(65 \%)$ of the cases occurred in women, though this figure may simply reflect a greater propensity among women to get tested.

"To date, no unexpected patterns have been identified in case demographics or vaccine characteristics," the agency said. "CDC is monitoring reported cases for clustering by patient demographics, geographic location, time since vaccination, vaccine type or lot number, and SARS-CoV-2 lineage.”

It added, "Breakthrough infections were reported in people of all ages eligible for vaccination, but a little over $40 \%$ of the infections were in people age 60 and up."

The cases were posted on the CDC's covid-19 vaccine breakthrough database by state health department investigators, and data are likely to be missing from cases from the past two weeks. They reflect only cases in fully vaccinated individuals who had received their second shot at least two weeks previously.

The figure is particularly encouraging, because these early vaccine recipients include much of the population deemed to be at elevated risk from the effects of the virus.

"All of the available vaccines have been proven effective at preventing severe illness, hospitalizations, and deaths," the CDC's statement said.

Anthony Fauci, director of the National Institute of Allergy and Infectious Diseases, said in a statement on the new figures, "You will see breakthrough infections in any vaccination, when you're vaccinating literally tens and tens and tens of millions of people. One of the important things that will be done and must be done is to sequence the genome of the virus that is the breakthrough virus."
An Israeli study awaiting peer review but posted online last week indicated that the South African variant (B.1.351) could pose an elevated risk of breakthrough infection in people given the Pfizer vaccine. ${ }^{1}$ Researchers found the variant in a much higher proportion of breakthrough infections in people who had been vaccinated than in infections among the unvaccinated.

The duration of protection conferred by coronavirus vaccines remains unknown, but the Biden administration's covid response chief science officer, David Kessler, told a congressional committee on 15 April that a third, booster shot of vaccine around the 12 month mark was looking increasingly likely.

"We are studying the durability of the antibody response," said Kessler. "It seems strong, but there is some waning of that and no doubt the variants challenge... they make these vaccines work harder. So I think, for planning purposes only, we should expect that we may have to boost."

In comments released the same day, Pfizer's chief executive officer, Albert Bourla, predicted that annual covid shots could well lie ahead. "A likely scenario is that there will be likely a need for a third dose, somewhere between 6 and 12 months, and then from there there will be an annual revaccination, but all of that needs to be confirmed. And, again, the variants will play a key role," he told CNBC's Bertha Coombs.

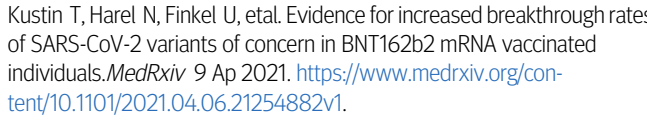

This article is made freely available for use in accordance with BMJ's website terms and conditions for the duration of the covid-19 pandemic or until otherwise determined by BMJ. You may use, download and print the article for any lawful, non-commercial purpose (including text and data mining) provided that all copyright notices and trade marks are retained. 